BMJ Open

Diabetes

Research

\& Care

\title{
Ethnic differences in beta cell function occur independently of insulin sensitivity and pancreatic fat in black and white men
}

\author{
Meera Ladwa (D) , ${ }^{1}$ Oluwatoyosi Bello, ${ }^{2}$ Olah Hakim, ${ }^{2}$ Fariba Shojaee-Moradie, ${ }^{3}$ \\ Maria Linda Boselli, ${ }^{4}$ Geoff Charles-Edwards, ${ }^{5}$ Janet Peacock (D) , ${ }^{6}$ \\ A Margot Umpleby, ${ }^{3}$ Stephanie A Amiel, ${ }^{1}$ Riccardo C Bonadonna, ${ }^{7,8}$ \\ Louise M Goff (10 ${ }^{2}$
}

To cite: Ladwa M, Bello 0, Hakim 0, et al. Ethnic differences in beta cell function occur independently of insulin sensitivity and pancreatic fat in black and white men. BMJ Open Diab Res Care 2021;9:e002034. doi:10.1136/ bmjdrc-2020-002034

Received 23 November 2020 Revised 21 January 2021 Accepted 11 February 2021
Check for updates

(c) Author(s) (or their employer(s)) 2021. Re-use permitted under CC BY-NC. No commercial re-use. See rights and permissions. Published by BMJ.

For numbered affiliations see end of article.

Correspondence to Dr Meera Ladwa; meera.ladwa@kcl.ac.uk

\section{ABSTRACT}

Introduction It is increasingly recognized that type 2 diabetes (T2D) is a heterogenous disease with ethnic variations. Differences in insulin secretion, insulin resistance and ectopic fat are thought to contribute to these variations. Therefore, we aimed to compare postprandial insulin secretion and the relationships between insulin secretion, insulin sensitivity and pancreatic fat in men of black West African (BA) and white European (WE) ancestry.

Research design and methods A cross-sectional, observational study in which 23 WE and 23 BA men with normal glucose tolerance, matched for body mass index, underwent a mixed meal tolerance test with $\mathrm{C}$ peptide modeling to measure beta cell insulin secretion, an MRI to quantify intrapancreatic lipid (IPL), and a hyperinsulinemiceuglycemic clamp to measure whole-body insulin sensitivity.

Results Postprandial insulin secretion was lower in BA versus WE men following adjustment for insulin sensitivity (estimated marginal means, BA vs WE: 40.5 (95\% Cl 31.8 to 49.2$) \times 10^{3}$ vs $56.4(95 \% \mathrm{Cl} 48.9$ to 63.8$) \times 10^{3} \mathrm{pmol} /$ $\mathrm{m}^{2}$ body surface area $\times 180 \mathrm{~min}, \mathrm{p}=0.008$ ). There was a significantly different relationship by ethnicity between IPL and insulin secretion, with a stronger relationship in WE than in $B A$ ( $r=0.59$ vs $r=0.39$, interaction $p=0.036$ ); however, IPL was not a predictor of insulin secretion in either ethnic group following adjustment for insulin sensitivity.

Conclusions Ethnicity is an independent determinant of beta cell function in black and white men. In response to a meal, healthy BA men exhibit lower insulin secretion compared with their WE counterparts for their given insulin sensitivity. Ethnic differences in beta cell function may contribute to the greater risk of T2D in populations of African ancestry.

\section{INTRODUCTION}

Populations of black African (BA) ethnicity have a higher prevalence ${ }^{12}$ of type 2 diabetes (T2D) compared with those of white European (WE) ethnicity. While there is evidence that part of the disparity is due to environmental

\section{Significance of this study}

What is already known about this subject?

- People of black African ancestry demonstrate hyperinsulinemia in response to intravenous glucose.

- This is thought to represent 'beta cell upregulation', an exaggerated insulin secretory response.

- Pancreatic fat accumulation is thought to be closely related to insulin hypersecretion in this ethnic group.

What are the new findings?

- In response to a physiological stimulus, when insulin sensitivity and insulin clearance are taken into account, black West African men secrete less insulin than their white European peers.

- Ethnicity is independently associated with insulin secretion.

- Pancreatic fat does not appear to play an independent role in insulin secretory response in either ethnic group.

How might these results change the focus of research or clinical practice?

- This study highlights the importance of methodology in the investigation of ethnic differences in beta cell function.

- The findings generate the hypothesis that relative impairments in beta cell function may contribute to the greater risk of type 2 diabetes in populations of African ancestry.

- The findings raise awareness of the heterogeneity of metabolic phenotypes in different ethnic groups.

and cultural factors such as socioeconomic status, diet and rates of obesity, the latter particularly in African-American women, ${ }^{3-5}$ studies which adjust for these variables have found persistently higher rates of T2D in $\mathrm{BA}$ populations. $^{67}$

Not only is the prevalence of T2D in BA higher compared with the general population, there are also distinctive features in 
their phenotype. BA develop T2D at an earlier age (up to 10 years younger) ${ }^{89}$ and at a lower body mass index (BMI) than WE, with modeling of UK Biobank data demonstrating that the risk of T2D in a WE subject with a BMI of $30 \mathrm{~kg} / \mathrm{m}^{2}$ is equivalent to the risk in a BA subject with a BMI of $26 \mathrm{~kg} / \mathrm{m}^{2}{ }^{10}$ BA exhibit a more aggressive phenotype of disease, with poorer glycemic control at diagnosis ${ }^{11}$ and higher rates of complications. ${ }^{12}$ They may have poorer responses to certain standard therapies ${ }^{13}$ and they are more likely to have atypical presentations of T2D such as ketosis-prone diabetes. These differences have important implications for screening, diagnosis and effective treatment in this ethnic group.

Physiological studies have identified characteristic features of insulin dynamics in BA ancestry populations which may help account for some of these differences. Healthy BA subjects are reported to exhibit 'beta cell upregulation', with hypersecretion of insulin in excess of what is required to overcome their prevailing insulin resistance. ${ }^{14-16}$ It has also been shown that in BA subjects, intrapancreatic lipid (IPL) is more strongly associated with greater compensatory insulin secretion ${ }^{17}$ and is a better predictor of glucose intolerance compared with other ethnic groups. ${ }^{18}$

However, the majority of these studies have been undertaken in African-American subjects and it is not known whether their findings can be equally applied to other populations of African ancestry, who are of diverse genetic admixture and who may have been exposed in utero or early life to undernutrition rather than energy excess. ${ }^{19} 20$ Furthermore, study methodologies may have a significant impact on the findings made. Beta cell hypersecretion in BA has been demonstrated largely using intravenous glucose stimulation techniques, ${ }^{21}$ but the intravenous route does not take account of the effects of factors such as neural and gut signals (including the incretin system), protein and fat ingestion, carbohydrate absorption rates, or first-pass splanchnic glucose extraction rates, all of which influence the complex dynamic system of beta cell insulin response in vivo. Second, multiple studies which have reported insulin hypersecretion in BA populations are based on measurements of peripheral insulin concentrations only. ${ }^{14} 2223$ Insulin clearance is lower in BA compared with WE subjects ${ }^{24} 25$; therefore measurement of peripheral insulin levels alone may overestimate beta cell insulin secretion in BA populations. The measurement of $\mathrm{C}$ peptide, which enables the effect of insulin clearance to be taken into account, is necessary when assessing beta cell function in this ethnic group.

Hence, our aim was to assess beta cell insulin secretion and its relationship with pancreatic fat in healthy men of black West African and white Northern European ethnicity using physiological methods which account for insulin clearance. To our knowledge, this is the first examination of the relationship between beta cell function and IPL in healthy BA adults which uses modeled C peptide data from mixed meal tolerance test (MMTT).

\section{MATERIALS AND METHODS}

\section{Study design}

The data were collected as part of 'Soul-Deep II', a crosssectional study of ethnic differences in the development of T2D in men from two ethnic groups, $\mathrm{WE}$ and BA. Metabolic assessments were performed at the Clinical Research Facility, King's College Hospital, London, UK, while MRI took place at Guy's Hospital, London, UK. Recruitment of subjects and data collection took place between April 2016 and May 2018. Recruitment was carried out through advertising in the local press and via general practice surgeries. All subjects provided written informed consent prior to the study.

\section{Subjects}

Subjects were invited to a screening assessment at the Clinical Research Facility at King's College Hospital, following a 10-hour fast, in order to undertake a screening questionnaire, anthropometric measurements and a 2-hour $75 \mathrm{~g}$ oral glucose tolerance test. Eligible subjects self-identified as either white (Northern) European or black (West) African (reporting four grandparents in the relevant ethnic group) and were normally glucosetolerant according to the WHO criteria. ${ }^{26}$ Anthropometric measurements included height, weight, waist circumference and seated blood pressure.

Exclusion criteria were a diagnosis of diabetes or impaired glucose tolerance; treatment with oral hypoglycemics, glucagon-like peptide 1 analogs, insulin, systemic steroids or beta blockers; any condition or medication considered by the investigators to have significant impact on the study protocol or outcomes; serum creatinine of $>150 \mathrm{mmol} / \mathrm{L}$; serum alanine transaminase level $>2.5$ fold above the upper limit of the reference range; and sickle cell disease (trait permitted). Participants were instructed to refrain from (1) strenuous physical activity for 48 hours, (2) alcohol consumption for 24 hours, and (3) food and drink (other than water) for at least 10 hours prior to the study visits. Study visits were completed in random order with a minimum of 7 days between visits. Participants were mandated to complete all study visits within a maximum period of 6 months.

\section{MMTT assessment of insulin secretion}

Following an overnight fast, a cannula was inserted into the antecubital fossa vein of the subject's non-dominant arm and two fasting blood samples drawn 10 min apart $(-10,0)$. A specified volume of Ensure Plus milkshake drink $(63 \%$ carbohydrate, $22 \%$ protein and $15 \%$ fat) (Abbott Nutrition, UK) was calculated based on six calories $(4 \mathrm{~mL})$ per kilogram body weight. The drink was consumed by the subject within a 5 min period. Blood samples were taken at 10, 20, 30, 40, 50, 60, 75, 90, 120, 150 , and $180 \mathrm{~min}$ for assessment of glucose, C peptide, insulin, glucagon and non-esterified fatty acid (NEFA) concentrations. Glucagon-like peptide 1 (GLP-1) and gastric inhibitory peptide (GIP) were assessed at $-10,0$, 30,60 , and $120 \mathrm{~min}$. 
Hyperinsulinemic-euglycemic clamp assessment of insulin sensitivity

The method has been reported..$^{27}$ In brief, participants were admitted to the Clinical Research Facility following an overnight fast and weighed in light clothing. Blood samples were taken at $-30,-20,-10$ and 0 min for basal assessments. A $240 \mathrm{~min}$ two-step clamp began at $0 \mathrm{~min}$. Euglycemia $(5.0 \mathrm{mmol} / \mathrm{L})$ was achieved using variable rate $20 \%$ (wt/vol) dextrose. Blood was drawn at 150,180, 210, 220, 230 and $240 \mathrm{~min}$ for assessment of plasma glucose concentration and insulin concentration. Whole-body insulin sensitivity was assessed in the second half of the $240 \mathrm{~min}$ two-step clamp (highdose insulin phase; $40 \mathrm{mU} / \mathrm{m}^{2}$ body surface area/min) and expressed as the $\mathrm{M}$ value corrected for steady-state insulin concentrations during this phase of the clamp $(\mathrm{M} / \mathrm{I})$.

\section{MRI assessment of IPL and visceral fat}

The MRI protocol has been reported..$^{28}$ In brief, a Dixon-based MRI sequence was used on a 1.5 Tesla Siemens scanner to obtain images from the neck to the knee (excluding the arms), and 384 contiguous, axial T1-weighted, gradient-echo images with a slice thickness of $3 \mathrm{~mm}$ were acquired, from which fat and water images were produced as part of the Dixon sequence. MRI data were analyzed using the open source image analysis software Horos V.1.1.7 (www.horosproject.org; accessed October 21, 2017) by a single analyst who was blinded to clinical data.

IPL was measured by selecting three circular regions of interest (ROIs) of approximately $1 \mathrm{~cm}^{2}$, placed on each of the head, body and tail regions of the pancreas. In each ROI, pancreatic fat fraction was quantified using the formula: $\% \mathrm{IPL}=(\mathrm{F} /(\mathrm{F}+\mathrm{W})) \times 100$, where $\mathrm{F}$ is the pixel signal intensity of the fat image and $\mathrm{W}$ is the pixel signal intensity of the water image. Mean IPL was calculated as the mean of the head, body and tail IPL.

Areas of visceral adipose tissue were quantified from an axial MRI at the L4-L5 spinal anatomical position.

\section{Biochemical analyses}

Plasma glucose concentrations were determined by an automated glucose analyzer (2300 STAT Glucose Analyzer, Yellow Springs Instrument, Ohio, USA); serum insulin concentrations by immunoassay using chemiluminescent technology (ADVIA Centaur System, Siemens Healthcare, Camberley, UK); serum C peptide concentrations by radioimmunoassay (Millipore, Hertfordshire, UK); GLP-1 and GIP (total) concentrations by fluorescent ELISA methods (EGLP-35K and EZHGIP-54K, Merck Millipore, UK); plasma glucagon by immunoassay (Meso Scale Discovery, Maryland, USA); and NEFA concentrations by enzymatic colorimetric assay (Wako Diagnostics, Richmond, Virginia), on an automated clinical chemistry analyzer (ILab 650; Instrument Laboratories, Holliston, Massachusetts).

\section{Calculations}

The incremental areas under the curve (iAUC) were calculated using the trapezoid rule for glucose, insulin, C peptide, glucagon, GIP, GLP-1 and NEFAs.

The glucose and $\mathrm{C}$ peptide curves during the meal tolerance test were modeled using reported methods in order to determine total postprandial endogenous beta cell insulin secretion $\left(\mathrm{AUC}_{\mathrm{ISR}}\right) .{ }^{29}{ }^{30}$ Model assessments were carried out using SAAM II V.1.2 software (SAAM Institute, Seattle, Washington).

During the meal test, mean (endogenous) insulin clearance was calculated according to the following formula ${ }^{30}$ :

$$
\text { Clearance }_{\text {Ins }}=\frac{A U C_{I S R}}{A U C_{1}+\left(I_{\text {Final }}-I_{\text {Basal }}\right) \cdot M R T_{\text {Ins }}}
$$

where $A U C_{I S R}$ is the area under the curve of insulin secretion rate, $A U C_{I}$ is the area under the curve of insulin concentration, $I_{\text {Final }}$ is the insulin concentration at the end of the study, $I_{\text {Basal }}$ is the insulin concentration at the beginning of the study, and $M R T_{I n s}$ is the mean residence time of insulin, which was assumed to be $18 \mathrm{~min}$ as reported in Navalesi et $a l .{ }^{31}$

\begin{tabular}{|c|c|c|c|}
\hline & $B A(n=23)$ & WE $(n=23)$ & $P$ value \\
\hline Age (years) & $30.7(12.0)$ & 35.9 (13.9) & 0.18 \\
\hline Weight (kg) & $84.1(14.6)$ & $86.5(16.5)$ & 0.60 \\
\hline BMI $\left(\mathrm{kg} / \mathrm{m}^{2}\right)$ & 26.7 (3.6) & $26.5(4.6)$ & 0.86 \\
\hline $\begin{array}{l}\text { Waist circumference } \\
\text { (cm) }\end{array}$ & $87.5(9.3)$ & $93.8(14.6)$ & 0.09 \\
\hline $\begin{array}{l}\text { Fasting glucose } \\
\text { (mmol/L) }\end{array}$ & $5.25(0.4)$ & $5.20(0.4)$ & 0.51 \\
\hline HbA1c (mmol/mol) & $37.0(5.3)$ & $35.9(2.9)$ & 0.37 \\
\hline HbA1c (\%) & $5.54(0.48)$ & $5.44(0.24)$ & 0.38 \\
\hline $\begin{array}{l}\text { Systolic blood } \\
\text { pressure (mm Hg) }\end{array}$ & $123.1(12.3)$ & $121.9(9.1)$ & 0.70 \\
\hline $\begin{array}{l}\text { Diastolic blood } \\
\text { pressure }(\mathrm{mm} \mathrm{Hg})\end{array}$ & 70.7 (11.5) & $71.1(8.2)$ & 0.88 \\
\hline $\begin{array}{l}\text { LDL cholesterol } \\
(\mathrm{mmol} / \mathrm{L})\end{array}$ & $2.66(0.87)$ & $2.99(0.82)$ & 0.19 \\
\hline $\begin{array}{l}\text { HDL cholesterol } \\
(\mathrm{mmol} / \mathrm{L})\end{array}$ & $1.30(0.42)$ & $1.27(0.31)$ & 0.75 \\
\hline $\begin{array}{l}\text { Total cholesterol } \\
(\mathrm{mmol} / \mathrm{L})\end{array}$ & $4.27(1.06)$ & $4.76(1.05)$ & 0.13 \\
\hline $\begin{array}{l}\text { Triglycerides } \\
\text { (mmol/L) }\end{array}$ & $0.68(0.25)$ & $1.10(0.56)$ & 0.003 \\
\hline
\end{tabular}

Values reported are from the participant screening visit. Data are presented as mean (SD).

Differences between the two ethnic groups determined using independent samples t-tests

BA, black African; BMI, body mass index; HbA1c, glycated hemoglobin; HDL, high-density lipoprotein; LDL, low-density lipoprotein; WE, white European. 
Table 2 Metabolic measurements in BA and WE men

\begin{tabular}{|c|c|c|c|c|}
\hline & BA $(n=23)$ & WE $(n=23)$ & $\begin{array}{l}\text { Mean difference or ratio of } \\
\text { geometric mean }(95 \% \mathrm{CI})\end{array}$ & $P$ value \\
\hline Fasting glucose (mmol/L) & $5.05(0.35)$ & $5.15(0.34)$ & $0.10(-0.11$ to 0.30$)$ & 0.36 \\
\hline iAUC glucose $(\mathrm{mmol} / \mathrm{L} \times 180 \mathrm{~min}) \ddagger$ & $92.7(68.4,125.6)$ & $96.8(63.1,148.4)$ & 1.04 (0.63 to 1.74$)$ & 0.86 \\
\hline Fasting insulin (pmol/L) $\ddagger$ & $51.7(41.4,64.6)$ & $54.5(42.3,70.1)$ & 1.05 (0.76 to 1.46$)$ & 0.75 \\
\hline iAUC insulin (pmol/L×180 min)‡ & $47.6(39.1,58.0) \times 10^{3}$ & $40.9(31.2,53.4) \times 10^{3}$ & 0.86 (0.62 to 1.18$)$ & 0.33 \\
\hline Fasting C peptide (nmol/L)‡ & $1.53(1.27,1.84)$ & $1.82(1.48,2.23)$ & $1.19(0.91$ to 1.56$)$ & 0.21 \\
\hline $\mathrm{AUC}_{\mathrm{C} \text { peptide }}(\mathrm{nmol} / \mathrm{L} \times 180 \mathrm{~min})$ & $207.7(81.3)$ & $271.2(175)$ & $63.5(-17.7$ to 144.7$)$ & 0.13 \\
\hline $\mathrm{AUC}_{\text {ISR }}\left(\mathrm{pmol} / \mathrm{m}^{2} \mathrm{BSA} \times 180 \mathrm{~min}\right) \ddagger$ & $41.1(35.5,47.6) \times 10^{3}$ & $46.5(36.7,58.9) \times 10^{3}$ & 1.13 (0.86 to 1.48$)$ & 0.37 \\
\hline Mean IPL $(\%)^{*} † \ddagger$ & $6.33(5.24,7.65)$ & $6.24(5.11,7.62)$ & 0.99 (0.75 to 1.29$)$ & 0.92 \\
\hline $\mathrm{M} / /^{*}(\mathrm{mg} / \mathrm{kg} \mathrm{FFM} / \mathrm{min}) /(\mathrm{pmol} / \mathrm{L})$ & $0.0171(0.0059)$ & $0.0189(0.0094)$ & $0.00184(-0.0030$ to 0.0066$)$ & 0.44 \\
\hline Insulin clearance $\left(\mathrm{mL} / \mathrm{m}^{2} \mathrm{BSA} / \mathrm{min}\right)$ & $697(171)$ & $819(173)$ & $122(18.3$ to 225$)$ & 0.006 \\
\hline Visceral adipose tissue $\left(\mathrm{cm}^{2}\right) \dagger$ & $48.2(35.5,64.6)$ & $79.0(55.0,112.2)$ & 1.64 (1.05 to 2.56$)$ & 0.035 \\
\hline Fasting NEFAs (mmol/L) $\ddagger$ & $0.38(0.29,0.51)$ & $0.42(0.33,0.54)$ & 1.09 (0.75 to 1.59$)$ & 0.63 \\
\hline AUC NEFAs (mmol/L×180 min) & $37.5(31.2,45.1)$ & $31.0(25.3,37.8)$ & $0.82(0.63$ to 1.07$)$ & 0.15 \\
\hline Fasting GLP-1 (pmol/L) & $16.2(9.0)$ & $16.8(8.5)$ & $0.61(-4.6$ to 5.9$)$ & 0.82 \\
\hline Fasting GIP (ng/L) & $164.6(71.0)$ & $202.5(69.7)$ & $37.9(-4.4$ to 80.2$)$ & 0.08 \\
\hline iAUC GLP-1 (pmol/L×180 min) & $1186.6(849.2,1658.1)$ & $1580.9(1232.3,2028.6)$ & 1.09 (0.75 to 1.59$)$ & 0.16 \\
\hline iAUC GIP (ng/L×180 min)‡ & 44937 (32 501, 62 116) & $36149(25509,51239)$ & 0.80 (0.51 to 1.28$)$ & 0.35 \\
\hline Fasting glucagon (ng/L) $\ddagger$ & $66.2(52.5,83.4)$ & $70.2(57.3,86.1)$ & 1.06 (0.79 to 1.43$)$ & 0.69 \\
\hline iAUC glucagon (ng/L×30 min)‡ & $564.3(319.3,997.2)$ & $813.8(615.2,1076)$ & 1.44 (0.78 to 2.68$)$ & 0.23 \\
\hline iAUC glucagon (ng/L×180 min)‡ & $4535(3003,6849)$ & $5111(3546,7367)$ & 1.13 (0.66 to 1.91$)$ & 0.65 \\
\hline
\end{tabular}

Data presented as mean (SD) and mean difference, or geometric mean $(95 \% \mathrm{Cl})$ and ratio of the geometric mean for log-transformed data. Differences between the two ethnic groups were determined using independent samples t-tests.

${ }^{*}$ Previously reported data. ${ }^{27} 28$

†BA $n=20$, WE $n=23$.

łLog-transformed.

AUC, area under the curve; $\mathrm{AUC}_{\mathrm{ISR}}$, total endogenous beta cell insulin secretory response; $\mathrm{BA}$, black African; BSA, body surface area; FFM, fat-free mass; GIP, gastric inhibitory polypeptide; GLP-1, glucagon-like peptide 1; iAUC, incremental area under the curve; IPL, intrapancreatic lipid; $M / /$, insulin sensitivity corrected for insulin concentrations; NEFAs, non-esterified fatty acids; WE, white European.

\section{Statistical analysis}

Data were collected as part of the SouL-Deep II study, which included 20 samples per group to allow the detection of a difference of 1 SD with a power of $90 \%$ and two-sided significance in the primary outcome variable of beta cell insulin secretory function. Log transformation was used on skewed variables that showed a significant deviation from normality to achieve a normal distribution prior to the use of parametric tests. Significance of differences in variables between the two ethnic groups was made using independent samples t-test. Insulin clearance was adjusted for insulin sensitivity $(\mathrm{M} / \mathrm{I})$ with one-way analysis of covariance.

The strength of linear relationships between variables of interest was assessed using Pearson's correlation. Interactions by ethnicity were assessed using a linear regression with ethnicity*IPL. Partial correlation analysis controlling for $\mathrm{M} / \mathrm{I}$ was performed.

A multiple regression model was run to predict insulin secretion $\left(\mathrm{AUC}_{\mathrm{ISR}}\right)$ with covariates of ethnicity, insulin sensitivity $(\mathrm{M} / \mathrm{I})$ and IPL. Analyses were conducted with SPSS V.25.0, and $p$ values $<0.05$ were considered statistically significant.

\section{RESULTS}

\section{Participant characteristics}

The characteristics of the 23 BA and 23 WE participants are presented in table 1 . Nine out of $23 \mathrm{BA}$ men were born in either Nigeria or Ghana, with the remainder born in the UK. The two ethnic groups were similar in age, weight and BMI and showed no differences in fasting glucose, blood pressure or low-density lipoprotein (table 1). BA men had lower fasting triglyceride levels (table 1 ) and lower visceral fat (table 2).

\section{Beta cell insulin secretory function}

The glucose, insulin and $\mathrm{C}$ peptide responses to the meal test are shown in figure 1 . There were no ethnic differences in the fasting or postprandial responses (iAUC) of glucose, insulin, C peptide or beta cell insulin secretion $\left(\mathrm{AUC}_{\mathrm{ISR}}\right)$ (figure 1, table 2$)$. However, 

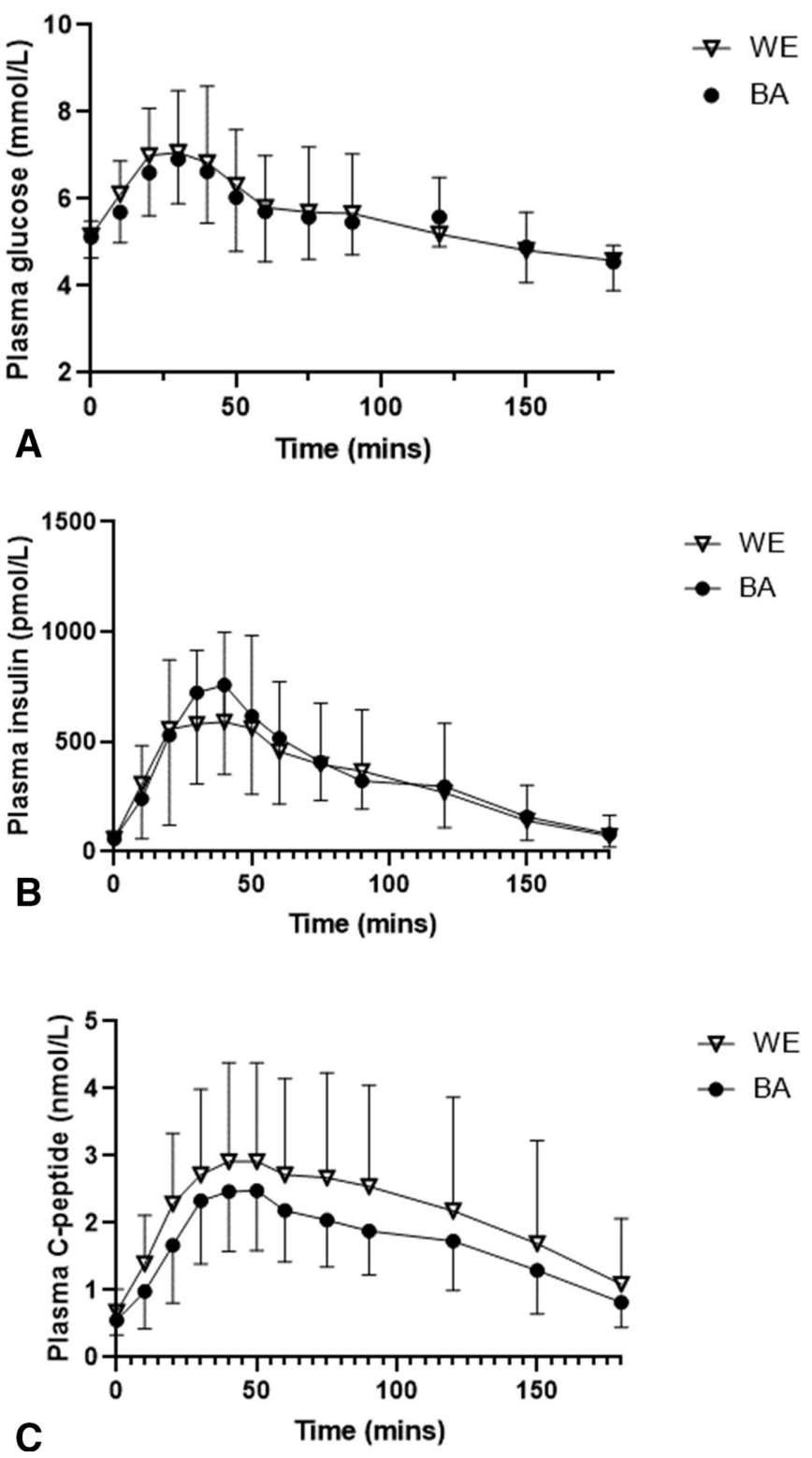

Figure 1 Plasma (A) glucose, (B) insulin and (C) C peptide responses by ethnic group during the mixed meal tolerance test (data shown are mean and SD). BA, black African; WE, white European.

after adjusting for insulin sensitivity $(\mathrm{M} / \mathrm{I})$, beta cell insulin secretion $\left(\mathrm{AUC}_{\mathrm{ISR}}\right)$ was lower in $\mathrm{BA}$ men (estimated marginal mean in BA vs WE: 40.5 (95\% CI 31.8 to 49.2$) \times 10^{3}$ vs $56.4(95 \%$ CI 48.9 to 63.8$) \times 10^{3}$ $\mathrm{pmol} / \mathrm{m}^{2}$ body surface area $\left.\times 180 \mathrm{~min}, \mathrm{p}=0.008\right)$.

\section{Insulin clearance}

The mean whole-body endogenous insulin clearance was significantly lower in BA men before and after adjustment for insulin sensitivity $(\mathrm{M} / \mathrm{I})(\mathrm{p}=0.006)$.

\section{Whole-body insulin sensitivity}

As previously reported, ${ }^{27}$ there were no significant ethnic differences in mean whole-body insulin sensitivity (expressed as $\mathrm{M} / \mathrm{I}$, included in table 2 for reference).

\section{Pancreatic fat}

As previously reported ${ }^{28}$ there were no significant ethnic differences in mean IPL (included in table 2 for reference).

\section{Incretin, glucagon and NEFA responses}

Fasting and postprandial GIP, GLP-1, glucagon and NEFAs are shown in table 2; there were no ethnic differences in either the fasting or postprandial responses.

\section{Relationships between beta cell insulin secretory function} and IPL

IPL was positively correlated with endogenous insulin secretion $\left(\mathrm{AUC}_{\mathrm{ISR}} ; \mathrm{r}=0.59, \mathrm{p}=0.003\right)$ in WE men; however, this correlation was not statistically significant in BA men $(r=0.32, p=0.206)$ and a significant interaction by ethnicity was found (interaction test, $\mathrm{p}=0.036$; figure $2 \mathrm{~A}$ ). Following adjustment for insulin sensitivity $(\mathrm{M} / \mathrm{I})$, there was no significant association between IPL and insulin secretion in either WE men $(\mathrm{r}=-0.067, \mathrm{p}=0.767)$ or $\mathrm{BA}$ men $(r=0.063, p=0.816)$. IPL was negatively correlated with insulin sensitivity in WE alone $(\mathrm{r}=-0.68, \mathrm{p}<0.005)$, but there was no interaction by ethnicity $(\mathrm{p}=0.114)$ (figure 2B).

A Mean IPL and $\mathrm{AUC}_{\text {ISR }}$ in WE: $\mathrm{r}=0.59, P=0.003$; $\mathrm{BA}: \mathrm{r}=0.39, P=0.101$

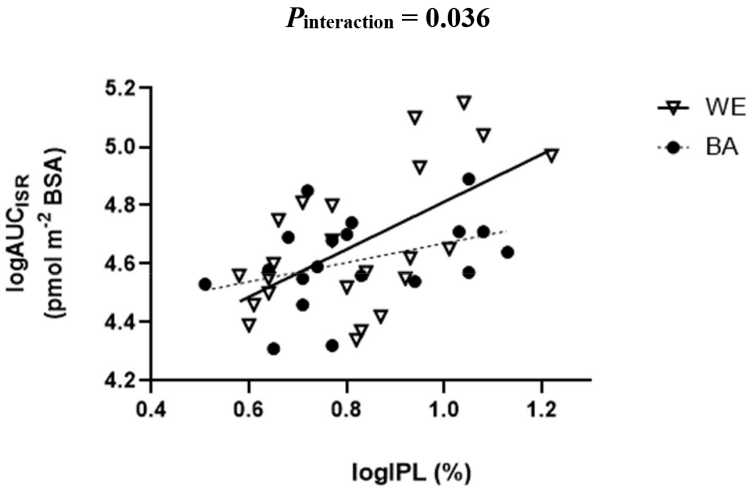

B Mean IPL and M/I in WE: $\mathrm{r}=-0.68, P<0.005$; $\mathrm{BA} \mathrm{r}=-0.43, P=0.088$

$$
P_{\text {interaction }}=0.114
$$

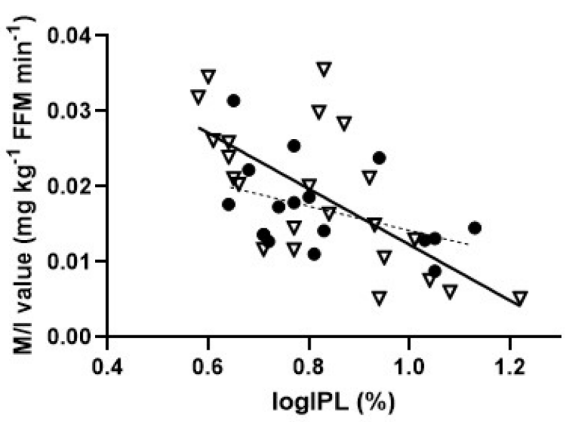

Figure 2 Relationships between IPL and (A) insulin secretion and $(B)$ insulin sensitivity by ethnicity. $A U C_{I S R}$, area under the curve of beta cell insulin secretion rate; BA, black African; BSA, body surface area; FFM, fat-free mass; IPL, intrapancreatic lipid; $M / I$, insulin sensitivity corrected for insulin concentrations; WE, white European. 
Table 3 Multiple regression analysis of predictors of beta cell insulin secretion

\begin{tabular}{|c|c|c|c|}
\hline \multirow{2}{*}{$\begin{array}{l}\text { Dependent variable: } \text { AUC }_{\text {ISR }} \\
\text { Model } 1, R^{2}=0.728\end{array}$} & \multirow[b]{3}{*}{$\beta$} & \multirow[b]{3}{*}{ t ratio } & \multirow[b]{3}{*}{$P$ value } \\
\hline & & & \\
\hline Independent variables & & & \\
\hline Ethnicity & -0.237 & -2.71 & 0.010 \\
\hline Insulin sensitivity & -0.850 & -7.78 & $<0.005$ \\
\hline IPL & -0.002 & -0.02 & 0.983 \\
\hline \multicolumn{4}{|l|}{ Model 2, R2=0.736 } \\
\hline \multicolumn{4}{|l|}{ Independent variables } \\
\hline Ethnicity & -0.27 & -2.5 & 0.021 \\
\hline Insulin sensitivity & -0.88 & -6.7 & $<0.005$ \\
\hline IPL & 0.036 & 0.28 & 0.785 \\
\hline VAT & 0.002 & -0.78 & 0.439 \\
\hline Age & 0.101 & 0.87 & 0.390 \\
\hline
\end{tabular}

$\mathrm{AUC}_{\mathrm{ISR}}$, area under the curve of beta cell insulin secretion rate; IPL, intrapancreatic lipid; VAT, visceral adipose tissue.

A linear multiple regression model was run to predict insulin secretion $\left(\mathrm{AUC}_{\mathrm{ISR}}\right)$, with ethnicity, pancreatic fat (IPL) and insulin sensitivity $(\mathrm{M} / \mathrm{I})$ as covariates (model 1 ; see table 3$)$. Overall, the model $\left(r^{2}=0.728\right)$ significantly predicted insulin secretion $(\mathrm{p}<0.005)$; both insulin sensitivity $(\mathrm{p}<0.005)$ and ethnicity $(\mathrm{p}=0.01)$ were independent predictors of insulin secretion, but pancreatic fat did not contribute significantly to the variation. Tests for multicollinearity between these variables were within tolerance levels (all variance inflation factors $<2.0$ ). Inclusion of age and visceral fat as covariates (model 2) did not significantly alter the model outputs.

\section{DISCUSSION}

Role of IPL in beta cell insulin secretion in WE and BA men with normal glucose tolerance

The role of pancreatic steatosis in metabolic disorders has received much attention, with the observation of the recovery of beta cell function and the reversal of T2D in association with the mobilization of pancreatic fat. ${ }^{32}$ There is evidence that the accumulation of intracellular triglyceride induces metabolic stress in the beta cells of the pancreas, leading to beta cell dysfunction and apoptosis. ${ }^{33} 34$ Clinical studies have also demonstrated an association between levels of IPL and impaired insulin responses in vivo. ${ }^{173536}$

In this context, the pathogenesis of glucose intolerance in BA populations appears paradoxical, as they demonstrate a relatively higher prevalence of $\mathrm{T} 2 \mathrm{D},{ }^{1}{ }^{2}$ despite lower levels of pancreatic fat when compared with WE populations. ${ }^{173738}$ We observed a positive correlation between IPL and insulin secretion in WE men, which was not found in BA men. However, following adjustment for the impact of insulin sensitivity, the association between IPL and insulin secretion was not significant in either ethnic group. In this study, with the acknowledgment that this was a healthy and non-obese population, pancreatic fat appears to be a proxy of insulin sensitivity and plays a surrogate role rather than directly affecting beta cell function. The role of IPL in the determination of beta cell function remains disputed, and other clinical studies have also failed to find a direct relationship in multiple ethnic groups,${ }^{3739-42}$ regardless of glucose tolerance status.

In contrast to our findings, Szczepaniak et $a l^{17}$ found that in BA subjects without diabetes, small increments in pancreatic fat were accompanied by a large linear increase in insulin secretion. They suggested that the strong relationship they observed between pancreatic triglyceride and insulin secretion in African ancestry adults was consistent with free fatty acid stimulation of the beta cell, either directly or secondarily to the promotion of insulin resistance. ${ }^{17}$ This was not the case in our subjects, in keeping with other investigations, ${ }^{37}$ despite the comparable numbers of participants. The reasons for our contrasting findings may be related to the populations under investigation; our BA subjects were mildly overweight with a mean BMI of $26.7(\mathrm{SD}=3.6) \mathrm{kg} / \mathrm{m}^{2}$, while the BA subjects in Szczepaniak et $a l^{17}$ were obese with a mean BMI of $32.2(\mathrm{SD}=2.2) \mathrm{kg} / \mathrm{m}^{2}$. Different techniques were used in the two studies; we used fatwater MRI to measure pancreatic fat fraction rather than magnetic spectroscopy; the former may be a superior modality for fat quantification owing to the irregular size and morphology of the pancreas. ${ }^{43}$ We modeled $\mathrm{C}$ peptide responses following an MMTT in place of using AIRg (acute insulin response to glucose) as a measure of insulin secretory response. The use of AIRg without $\mathrm{C}$ peptide measurement may overestimate beta cell insulin secretion due to the significantly lower rates of insulin clearance in subjects of African ancestry ${ }^{21}$; ; hence, our methods overcame this particular limitation. Lastly, we adjusted our findings for insulin sensitivity, enabling examination of the relationship between IPL and insulin secretion while taking prevailing insulin sensitivity into account as a confounding factor.

\section{Ethnic comparison of postprandial insulin secretion}

In BA subjects with both normal glucose tolerance and T2D, studies have consistently recognized a hyperinsulinemic response to glucose in comparison with their WE peers. ${ }^{1422}{ }^{44-46}$ While the hyperinsulinemia of BA populations is in part a compensation for insulin resistance, they also appear to have an exaggerated beta cell response, with excessive insulin secretion independent of insulin sensitivity. ${ }^{14-16}{ }^{47}$ Such an observation has led to the hypothesis of 'upregulated beta cell function' in BA subjects, whereby the beta cell appears to be excessively responsive to glucose. ${ }^{164748}$

By contrast, in this study we found that there was no evidence of postprandial insulin hypersecretion in BA men and, against our expectations, insulin secretion was lower in BA compared with WE men following adjustment for insulin sensitivity. Furthermore, the peripheral 
insulin response to oral nutrients in BA subjects did not replicate the very marked hyperinsulinemia both we and others have seen in response to intravenous glucose challenges in this ethnic group and indeed in these same study subjects. ${ }^{24} 49-51$ The absence of hyperinsulinemia in $\mathrm{BA}$ in response to a mixed meal-in comparison with the profound hyperinsulinemia of the same study subjects in response to intravenous glucose ${ }^{24}$ - has also been reported elsewhere. ${ }^{52}$

The discrepancy may be explained by the multiple variables which do not come into play during intravenous glucose stimulation tests, predominantly gut signals, although in this study no significant ethnic differences were found in either fasting or postprandial GLP-1 or GIP. Intravenous and oral challenges also differ in the magnitude, duration and kinetics of the glycemic load which is delivered to the beta cell and which during the MMTT is not under direct control of the investigator. Evidence for beta cell hypersecretion in BA is far more variable following oral compared with intravenous tests, ${ }^{21}$ perhaps because of these factors. None of the studies to date which have used the MMTT have shown hypersecretion of total endogenous insulin in BA adults, ${ }^{49} 53-56$ while multiple investigators have documented relatively lower $\mathrm{C}$ peptide responses in response to oral glucose in BA subjects. ${ }^{57-59}$ Therefore, the preponderance of intravenous studies in the literature may not be wholly representative of the underlying physiology of BA populations.

Examining the data following adjustment for insulin sensitivity, it appears that BA men exhibit lower beta cell insulin secretion during the meal in the context of lower insulin clearance, thereby maintaining a postprandial glucose and insulin profile very similar to that of WE men. The lower rates of insulin clearance in BA subjects, a widely and consistently reported phenomenon, ${ }^{16} 2560$ may from this perspective be an appropriate and adaptive response to maintain peripheral insulin levels in the face of lower beta cell insulin secretion. We have previously demonstrated comparatively greater insulin secretory deficits in BA compared with WE men with T2D. ${ }^{30} \mathrm{We}$ postulate that the comparatively reduced insulin secretion in healthy BA men may contribute to their risk of glucose intolerance should insulin resistance develop, a hypothesis that has also been proposed by others. ${ }^{61}$

The reasons for the marked differences between our study findings and many others should be addressed. The majority of the literature in this area pertains to African-American populations (30 out of 41 studies in a systematic review ${ }^{21}$ ), with relatively few studies in other populations of African ancestry; our participants were strictly of direct West African ancestry, reporting both parents and four grandparents born in countries of West Africa (Ghana and Nigeria). Differences in both genetic traits and environment (such as diet and obesity rates) may underlie distinct metabolic phenotypes in BA. A recently identified novel genomic locus associated with T2D in a population consisting of Nigerians, Ghanaians and Kenyans is linked to beta cell apoptosis and impaired insulin secretory responses ${ }^{62}$ and the typical phenotype of sub-Saharan Africans with T2D is leaner, younger and characterized by insulin deficiency. ${ }^{61}{ }^{63}$ A comparative study has identified insulin responses two to three times higher in African-Americans without diabetes compared with native Nigerians, ${ }^{64}$ while insulin deficiency rather than insulin hypersecretion has been identified in healthy black South Africans compared with their white counterparts. ${ }^{6566}$ In accordance with these observations, it is hypothesized that indigenous BA populations are more vulnerable to beta cell dysfunction, possibly due to the transgenerational effects of perinatal malnutrition. ${ }^{67}$

Sex differences in BA populations may also come into play. The preponderance of literature in this area pertains to women, who make up approximately $75 \%$ of BA subjects studied. ${ }^{21}$ For example, in contrast to our findings, Chung et a $\bar{l}^{\tilde{3}}$ found a relative peripheral hyperinsulinemia in African immigrant/AfricanAmerican women in response to a mixed meal. ${ }^{68}$ This may be explained by different responses to glucose in BA men and women, with studies consistently finding greater hyperinsulinemia in women. ${ }^{55}{ }^{69-72}$ We note with interest that in a recent investigation by Armiyaw et $a l^{15}$ it was only the African-American women who contributed to ethnic differences observed in beta cell responsivity, not the men. As their study was neither designed nor powered to examine interactions by sex, Armiyaw et $a l^{15}$ rightly advised caution when interpreting these findings. Further work examining the interactions between sex and ethnicity in BA groups is warranted.

\section{Strengths and limitations}

The strengths of this study include the well-matched, strictly characterized subject groups and the use of a physiological method, the mixed meal test, to assess insulin secretory function. Another strength is the use of sophisticated techniques, including $\mathrm{C}$ peptide modeling and the reference standard hyperinsulinemic-euglycemic clamp, to determine beta cell function in the context of insulin sensitivity and to take ethnic differences in insulin clearance into account. In terms of limitations, while the study was powered for the main outcome variable of beta cell insulin secretion, we were not powered to examine the associations between variables and therefore we may have been unable to detect some relationships. We also acknowledge that, as the study was performed in men only, there are limitations to its generalizability; however, the majority of the literature on ethnic differences between WE and BA has examined women ${ }^{21}$ and therefore our choice to study men only was a conscious attempt to address this potential bias in the literature.

\section{CONCLUSIONS}

This detailed metabolic investigation of a well-matched group of normally glucose-tolerant men of European and African ancestry found that healthy black West African men do not hypersecrete insulin in response to a meal 
stimulus; indeed following adjustment for insulin sensitivity, both their endogenous insulin secretion and insulin clearance rates are lower in comparison with their $\mathrm{WE}$ counterparts, resulting in similar postprandial systemic insulin and glucose profiles in both ethnic groups. While ethnicity and insulin sensitivity were independently associated with insulin secretion rates, pancreatic fat content was not.

We recognize that our findings run counter to much of the literature, where the consensus is that BA populations hypersecrete insulin and that pancreatic fat is a powerful determinant of their beta cell function; emerging evidence, however, shows that these established findings are not necessarily as consistent as initially thought. ${ }^{2473}$ In some African ancestry populations, a relative deficiency of beta cell insulin secretion in the context of their insulin sensitivity may contribute to their risk of developing glucose intolerance. A better understanding of ethnic-specific differences in metabolism in both health and early disease will be key to refining prevention and treatment options, allowing an evidence-based prediction of responses which can then be tested in interventional studies.

\section{Author affiliations}

${ }^{1}$ Department of Diabetes, Faculty of Life Sciences and Medicine, King's College London, London, UK

${ }^{2}$ Diabetes and Nutritional Sciences Division, Faculty of Life Sciences and Medicine, King's College London, London, UK

${ }^{3}$ Faculty of Health and Medical Sciences, University of Surrey, Guildford, UK ${ }^{4}$ Department of Medicine, Università degli Studi di Verona, Verona, Italy ${ }^{5}$ School of Biomedical Engineering and Imaging Sciences, King's College London, London, UK

${ }^{6}$ Department of Epidemiology, Dartmouth College Geisel School of Medicine, Hanover, New Hampshire, USA

${ }^{7}$ Department of Medicine and Surgery, University of Parma, Parma, Italy

${ }^{8}$ Endocrinologia e Malattie del Metabolismo, Azienda Ospedaliero-Universitaria di Parma, Parma, Italy

Acknowledgements The authors would like to thank A Pernet, B Wilson and M Henderson-Wilson (Diabetes Research Group, King's College Hospital, London, UK) for assisting with the metabolic assessments; T Dew (ViaPath, King's College Hospital) for assistance with sample processing and laboratory analysis; $L$ Coppin and N Jackson (University of Surrey, Guildford, UK) for assistance with analysis of the glucose enrichments; E Giemsa (Clinical Research Facility, King's College Hospital) for accommodating participant visits; the staff of the Clinical Research Facility at King's College Hospital for help in performing the studies; and the study participants for their time and commitment.

Contributors LMG formulated the research question, designed the study, and supervised the data collection and interpretation. SAA formulated the research question and designed the study. JP formulated the research question, designed the study, and provided statistical advice. AMU formulated the research question and designed the study. RCB supervised the modeling analysis and contributed to interpretation. OB supervised the data collection, performed the metabolic assessments and undertook data analysis. FS-M supervised the data collection and undertook data analysis. ML supervised the data collection, performed the metabolic assessments, undertook data analysis and interpretation, and drafted the manuscript. $\mathrm{OH}$ undertook MRI data analysis. GC-E coordinated MRI data acquisition. MLB undertook modeling analysis. All authors contributed to the intellectual content and reviewed the final version of the submitted manuscript. LMG is the guarantor of this work, had full access to all the data and takes full responsibility for the integrity of the data and the accuracy of data analysis.

Funding This work was funded by a Diabetes UK project grant (14/0004967). JP is supported by the NIHR Biomedical Research Centre based at Guy's and St
Thomas' NHS Foundation Trust and King's College London and is an NIHR Senior Investigator.

Competing interests SAA has served on advisory boards for Novo Nordisk, Medtronic and Roche. The other authors declare no conflict of interest.

Patient consent for publication Not required.

Ethics approval The study was approved by the London Bridge National Research Ethics Committee (15/LO/1121).

Provenance and peer review Not commissioned; externally peer reviewed.

Data availability statement Data are available upon reasonable request to LMG at louise.goff@kcl.ac.uk.

Open access This is an open access article distributed in accordance with the Creative Commons Attribution Non Commercial (CC BY-NC 4.0) license, which permits others to distribute, remix, adapt, build upon this work non-commercially, and license their derivative works on different terms, provided the original work is properly cited, appropriate credit is given, any changes made indicated, and the use is non-commercial. See: http://creativecommons.org/licenses/by-nc/4.0/.

\section{ORCID iDs}

Meera Ladwa http://orcid.org/0000-0002-2775-342X

Janet Peacock http://orcid.org/0000-0002-0310-2518

Louise M Goff http://orcid.org/0000-0001-9633-8759

\section{REFERENCES}

1 Tillin T, Forouhi NG, McKeigue PM, et al. Southall and Brent revisited: cohort profile of sabre, a UK population-based comparison of cardiovascular disease and diabetes in people of European, Indian Asian and African Caribbean origins. Int J Epidemiol 2012;41:33-42.

2 Brancati FL, Kao WH, Folsom AR, et al. Incident type 2 diabetes mellitus in African American and white adults: the Atherosclerosis risk in Communities study. JAMA 2000;283:2253-9.

3 Lipton RB, Liao Y, Cao G, et al. Determinants of incident noninsulin-dependent diabetes mellitus among blacks and whites in a national sample. The NHANES I epidemiologic follow-up study. Am J Epidemiol 1993;138:826-39.

4 Signorello LB, Schlundt DG, Cohen SS, et al. Comparing diabetes prevalence between African Americans and whites of similar socioeconomic status. Am J Public Health 2007;97:2260-7.

5 Harding S, Elia C, Huang P. Global cities and cultural diversity: challenges and opportunities for young people's nutrition. Proc Nutr Soc 2018:1-14.

6 Brancati FL, Whelton PK, Kuller LH, et al. Diabetes mellitus, race, and socioeconomic status. A population-based study. Ann Epidemiol 1996;6:67-73.

7 Egede LE, Mueller M, Echols CL, et al. Longitudinal differences in glycemic control by race/ethnicity among veterans with type 2 diabetes. Med Care 2010;48:527-33.

$8 \mathrm{Ng} \mathrm{M}$, Fleming T, Robinson M, et al. Global, regional, and national prevalence of overweight and obesity in children and adults during 1980-2013: a systematic analysis for the global burden of disease study 2013. Lancet 2014;384:766-81.

9 Winkley K, Thomas SM, Sivaprasad S, et al. The clinical characteristics at diagnosis of type 2 diabetes in a multi-ethnic population: the South London diabetes cohort (SOUL-D). Diabetologia 2013;56:1272-81.

10 Ntuk UE, Gill JMR, Mackay DF, et al. Ethnic-Specific obesity cutoffs for diabetes risk: cross-sectional study of 490,288 UK Biobank participants. Diabetes Care 2014;37:2500-7.

11 Harris MI, Eastman RC, Cowie CC, et al. Racial and ethnic differences in glycemic control of adults with type 2 diabetes. Diabetes Care 1999;22:403-8.

12 Harris EL, Sherman SH, Georgopoulos A. Black-white differences in risk of developing retinopathy among individuals with type 2 diabetes. Diabetes Care 1999;22:779-83.

13 Arslanian S, El Ghormli L, Bacha F, et al. Adiponectin, insulin sensitivity, $\beta$-cell function, and racial/ethnic disparity in treatment failure rates in today. Diabetes Care 2017;40:85-93.

14 Kodama K, Tojjar D, Yamada S, et al. Ethnic differences in the relationship between insulin sensitivity and insulin response: a systematic review and meta-analysis. Diabetes Care 2013;36:1789-96.

15 Armiyaw L, Sarcone C, Fosam A. Increased $\beta$-cell responsivity independent of insulin sensitivity in healthy African American adults. 
J Clin Endocrinol Metab 2020;105. doi:10.1210/clinem/dgaa234. [Epub ahead of print: $01 \mathrm{Jul} 2020$ ].

16 Hannon TS, Bacha F, Lin Y, et al. Hyperinsulinemia in AfricanAmerican adolescents compared with their American white peers despite similar insulin sensitivity: a reflection of upregulated beta-cell function? Diabetes Care 2008;31:1445-7.

17 Szczepaniak LS, Victor RG, Mathur R, et al. Pancreatic steatosis and its relationship to $\beta$-cell dysfunction in humans: racial and ethnic variations. Diabetes Care 2012;35:2377-83.

18 Toledo-Corral CM, Alderete TL, $\mathrm{Hu} \mathrm{HH}$, et al. Ectopic fat deposition in prediabetic overweight and obese minority adolescents. $J$ Clin Endocrinol Metab 2013;98:1115-21.

19 Gower BA, Fernández JR, Beasley TM, et al. Using genetic admixture to explain racial differences in insulin-related phenotypes. Diabetes 2003;52:1047-51.

20 Cheng C-Y, Reich D, Haiman CA, et al. African ancestry and its correlation to type 2 diabetes in African Americans: a genetic admixture analysis in three U.S. population cohorts. PLoS One 2012; 7:e32840.

21 Ladwa M, Hakim O, Amiel SA, et al. A systematic review of beta cell function in adults of black African ethnicity. $J$ Diabetes Res 2019;2019:17.

22 Haffner SM, D'Agostino R, Saad MF, et al. Increased insulin resistance and insulin secretion in nondiabetic African-Americans and Hispanics compared with non-Hispanic whites. the insulin resistance atherosclerosis study. Diabetes 1996;45:742-8.

23 Jensen CC, Cnop M, Hull RL, et al. Beta-Cell function is a major contributor to oral glucose tolerance in high-risk relatives of four ethnic groups in the U.S. Diabetes 2002;51:2170-8.

24 Ladwa M, Bello O, Hakim O, et al. Insulin clearance as the major player in the hyperinsulinaemia of black African men without diabetes. Diabetes Obes Metab 2020;22:1808-1817.

25 Piccinini F, Polidori DC, Gower BA, et al. Hepatic but not extrahepatic insulin clearance is lower in African American than in European American women. Diabetes 2017;66:2564-70.

26 Alberti KG, Zimmet PZ, Definition ZPZ. Definition, diagnosis and classification of diabetes mellitus and its complications. Part 1: diagnosis and classification of diabetes mellitus provisional report of a who consultation. Diabet Med 1998;15:539-53.

27 Bello O, Ladwa M, Hakim O, et al. Differences in the link between insulin sensitivity and ectopic fat in men of black African and white European ethnicity. Eur J Endocrinol 2020;182:91-101.

28 Hakim O, Bello O, Ladwa M, et al. Ethnic differences in hepatic, pancreatic, muscular and visceral fat deposition in healthy men of white European and black West African ethnicity. Diabetes Res Clin Pract 2019;156:107866.

29 Malandrucco I, Pasqualetti P, Giordani I, et al. Very-Low-Calorie diet: a quick therapeutic tool to improve $\beta$ cell function in morbidly obese patients with type 2 diabetes. Am J Clin Nutr 2012;95:609-13.

30 Mohandas C, Bonadonna R, Shojee-Moradie F, et al. Ethnic differences in insulin secretory function between black African and white European men with early type 2 diabetes. Diabetes Obes Metab 2018;20:1678-87.

31 Navalesi R, Pilo A, Ferrannini E. Kinetic analysis of plasma insulin disappearance in nonketotic diabetic patients and in normal subjects. A tracer study with $125 \mathrm{I}$-insulin. J Clin Invest 1978;61:197-208.

32 Taylor R, Al-Mrabeh A, Sattar N. Understanding the mechanisms of reversal of type 2 diabetes. Lancet Diabetes Endocrinol 2019;7:726-36.

33 Lee $\mathrm{Y}$, Hirose $\mathrm{H}$, Ohneda M, et al. Beta-Cell lipotoxicity in the pathogenesis of non-insulin-dependent diabetes mellitus of obese rats: impairment in adipocyte-beta-cell relationships. Proc Natl Acad Sci U S A 1994;91:10878-82.

34 Sharma RB, Alonso LC. Lipotoxicity in the pancreatic beta cell: not just survival and function, but proliferation as well? Curr Diab Rep 2014;14:492

35 Tushuizen ME, Bunck MC, Pouwels PJ, et al. Pancreatic fat content and beta-cell function in men with and without type 2 diabetes. Diabetes Care 2007:30:2916-21.

36 Heni M, Machann J, Staiger $\mathrm{H}$, et al. Pancreatic fat is negatively associated with insulin secretion in individuals with impaired fasting glucose and/or impaired glucose tolerance: a nuclear magnetic resonance study. Diabetes Metab Res Rev 2010;26:200-5.

37 Lê K-A, Ventura EE, Fisher JQ, et al. Ethnic differences in pancreatic fat accumulation and its relationship with other fat depots and inflammatory markers. Diabetes Care 2011;34:485-90.

38 Lingvay I, Szczepaniak E, Szczepaniak L. Ethnic diversity in betacell function susceptibility to pancreatic triglyceride levels: pilot investigation. J Diabetes Metab 2014;05:2.
39 van der Zijl NJ, Goossens GH, Moors CCM, et al. Ectopic fat storage in the pancreas, liver, and abdominal fat depots: impact on $\beta$-cell function in individuals with impaired glucose metabolism. J Clin Endocrinol Metab 2011:96:459-67.

40 Wong VW-S, Wong GL-H, Yeung DK-W, et al. Fatty pancreas, insulin resistance, and $\beta$-cell function: a population study using fat-water magnetic resonance imaging. Am J Gastroenterol 2014;109:589-97.

41 Begovatz P, Koliaki C, Weber K, et al. Pancreatic adipose tissue infiltration, parenchymal steatosis and beta cell function in humans. Diabetologia 2015;58:1646-55.

42 Li YX, Sang YQ, Sun Y, et al. Pancreatic fat is not significantly correlated with $\beta$-cell dysfunction in patients with new-onset type 2 diabetes mellitus using quantitative computed tomography. Int $J$ Med Sci 2020;17:1673-82.

$43 \mathrm{Hu} \mathrm{HH}$, Kim H-W, Nayak KS, et al. Comparison of fat-water MRI and single-voxel MRS in the assessment of hepatic and pancreatic fat fractions in humans. Obesity 2010;18:841-7.

44 Chiu KC, Cohan P, Lee NP, et al. Insulin sensitivity differs among ethnic groups with a compensatory response in beta-cell function. Diabetes Care 2000;23:1353-8

45 Torréns JI, Skurnick J, Davidow AL, et al. Ethnic differences in insulin sensitivity and beta-cell function in premenopausal or early perimenopausal women without diabetes: the study of women's health across the nation (Swan). Diabetes Care 2004;27:354-61.

46 Arslanian S, Suprasongsin C. Differences in the in vivo insulin secretion and sensitivity of healthy black versus white adolescents. $J$ Pediatr 1996;129:440-3.

47 Hasson BR, Apovian C, Istfan N. Racial/Ethnic differences in insulin resistance and beta cell function: relationship to racial disparities in type 2 diabetes among African Americans versus Caucasians. Curr Obes Rep 2015;4:241-9.

48 Bacha F, Gungor N, Lee S, et al. Type 2 diabetes in youth: are there racial differences in $\beta$-cell responsiveness relative to insulin sensitivity? Pediatr Diabetes 2012;13:259-65.

49 Stefan N, Stumvoll M, Weyer C, et al. Exaggerated insulin secretion in Pima Indians and African-Americans but higher insulin resistance in Pima Indians compared to African-Americans and Caucasians. Diabet Med 2004;21:1090-5.

50 Cruickshank JK, Cooper J, Burnett M, et al. Ethnic differences in fasting plasma $\mathrm{C}$-peptide and insulin in relation to glucose tolerance and blood pressure. Lancet 1991;338:842-7.

51 Goff LM, Whyte MB, Samuel M, et al. Significantly greater triglyceridemia in black African compared to white European men following high added fructose and glucose feeding: a randomized crossover trial. Lipids Health Dis 2016;15:145.

52 Hasson RE, Adam TC, Davis JN, et al. Ethnic differences in insulin action in obese African-American and Latino adolescents. $J$ Clin Endocrinol Metab 2010;95:4048-51.

53 Chung ST, Galvan-De La Cruz M, Aldana PC, et al. Postprandial insulin response and clearance among black and white women: the federal women's study. J Clin Endocrinol Metab 2019;104:181-92.

54 Punyadeera C, Crowther NJ, van der Merwe M-T, et al. Metabolic response to a mixed meal in obese and lean women from two South African populations. Obes Res 2002;10:1207-16.

55 Goff LM, Griffin BA, Lovegrove JA, et al. Ethnic differences in beta-cell function, dietary intake and expression of the metabolic syndrome among UK adults of South Asian, black African-Caribbean and white-European origin at high risk of metabolic syndrome. Diab Vasc Dis Res 2013:10:315-23.

56 Higgins PB, Férnández JR, Garvey WT, et al. Entero-insular axis and postprandial insulin differences in African American and European American children. Am J Clin Nutr 2008;88:1277-83.

57 Tricò D, Galderisi A, Mari A, et al. Intrahepatic fat, irrespective of ethnicity, is associated with reduced endogenous insulin clearance and hepatic insulin resistance in obese youths: a cross-sectional and longitudinal study from the Yale pediatric NAFLD cohort. Diabetes Obes Metab 2020;22:1628-38.

58 Reimann M, Schutte AE, Huisman HW, et al. Ethnic differences in C-peptide secretion but not in non-esterified fatty acid metabolism in pre-menopausal women with and without abdominal obesity. Diabetes Res Clin Pract 2007:77:62-9.

59 Chen X, Scholl TO. Ethnic differences in C-peptide/insulin/glucose dynamics in young pregnant women. $J$ Clin Endocrinol Metab 2002;87:4642-6.

60 Osei K, Schuster DP, Owusu SK, et al. Race and ethnicity determine serum insulin and $\mathrm{C}$-peptide concentrations and hepatic insulin extraction and insulin clearance: comparative studies of three populations of West African ancestry and white Americans. Metabolism 1997:46:53-8. 
61 Joffe B, Panz VR, Wing JR. Pathogenesis of non-insulin-dependent diabetes mellitus in the black population of southern Africa. The Lancet 1992;340:460-2.

62 Adeyemo AA, Zaghloul NA, Chen G, et al. ZRANB3 is an africanspecific type 2 diabetes locus associated with beta-cell mass and insulin response. Nat Commun 2019;10:3195.

63 Kibirige D, Lumu W, Jones AG, et al. Understanding the manifestation of diabetes in sub Saharan Africa to inform therapeutic approaches and preventive strategies: a narrative review. Clin Diabetes Endocrinol 2019;5:2.

64 Osei K, Cottrell DA, Adenuwon CA, et al. Serum insulin and glucose concentrations in people at risk for type II diabetes. A comparative study of African Americans and Nigerians. Diabetes Care 1993;16:1367-75.

65 Shires R, Joffe BI, Seftel HC. Maximal pancreatic beta-cell stimulation and the counter-regulatory hormonal responses in South African black and white obese subjects. S Afr Med J 1985;67:845-7.

66 Rubenstein $\mathrm{AH}$, Seftel HC, Miller K, et al. Metabolic response to oral glucose in healthy South African white, Indian, and African subjects. Br Med J 1969;1:748-51.

67 Joffe B, Zimmet P. The thrifty genotype in type 2 diabetes. Endocrine 1998;9:139-41.
68 Chung ST, Galvan-De La Cruz M, Aldana PC. Postprandial insulin response and clearance among black and white women: The Federal Women's Study. J Clin Endocrinol Metab 2018.

69 Gaillard TR, Schuster DP, Osei K. Gender differences in cardiovascular risk factors in obese, nondiabetic first degree relatives of African Americans with type 2 diabetes mellitus. Ethn Dis 1998;8:319-30.

70 Goedecke JH, George C, Veras K, et al. Sex differences in insulin sensitivity and insulin response with increasing age in black South African men and women. Diabetes Res Clin Pract 2016;122:207-14.

71 Falkner B, Hulman S, Kushner H. Gender differences in insulinstimulated glucose utilization among African-Americans. Am J Hypertens 1994;7:948-52.

72 Sumner AE, Kushner $\mathrm{H}$, Sherif KD, et al. Sex differences in AfricanAmericans regarding sensitivity to insulin's glucoregulatory and antilipolytic actions. Diabetes Care 1999;22:71-7.

73 Hakim O, Bonadonna RC, Mohandas C, et al. Associations between pancreatic lipids and $\beta$-cell function in black African and white European men with type 2 diabetes. J Clin Endocrinol Metab 2019;104:1201-10. 